\title{
Analysis of Current Environmental Impact Assessment System in Rwanda
}

\author{
Jean Paul Nkundabose ${ }^{1, *}$, Theogene Ingabire ${ }^{2}$, Elie Nshimiyimana ${ }^{3}$, Jean Jacques Yves Niyotwizera ${ }^{3}$, \\ Gratien Twagirayezu ${ }^{4}$ \\ ${ }^{1}$ School of Environmental Science and Engineering, Suzhou University of Science and Technology, China \\ ${ }^{2}$ Department of Environmental Studies, Faculty of Science, University of Delhi, India \\ ${ }^{3}$ College of Science and Technology, University of Rwanda, Rwanda \\ ${ }^{4}$ School of Environmental and Municipal Engineering, Lanzhou Jiaotong University, China
}

Received April 12, 2020; Revised June 15, 2020; Accepted July 1, 2020

Copyright $\odot 2020$ by authors, all rights reserved. Authors agree that this article remains permanently open access under the terms of the Creative Commons Attribution License 4.0 International License

\begin{abstract}
Following its introduction in the developed countries, Environmental Impact Assessment (EIA) is now established in many developing countries. However, EIA systems in developing countries vary greatly in procedures and practice. The concept of EIA in Rwanda was introduced through the establishment of Rwanda Environmental Management Authority (REMA). Under Organic Law No.04/2005 of 08/04/2005 Article 64, REMA came in to coordinate and oversee all aspects of environmental management for sustainable development in the country. Currently, the EIA department was transferred from REMA to Rwanda Development Board (RDB). By a set of criteria, the present work aims to evaluate and analyze the EIA system in Rwanda, focusing on process and methodology, highlighting some challenges of EIA practice and suggesting some recommendations. Given the nature of the work, the evaluation was based on the review of literature, investigation of legislative and administrative framework. EIA practice in Rwanda enhances the developmental projects to be viable and environmentally friendly. In regard of implementation challenge, environment-related government bodies are recommended to strengthen environmental monitoring and audits. Findings of this study could contribute to wider international experience of EIA performance in developing countries.
\end{abstract}

Keywords EIA, Rwanda, Environmental Monitoring, REMA, Criteria

\section{Introduction}

In 1970, the EIA was first introduced to the United States and has since rapidly entered the world [17, 37]. In the 1990s, it marked an unprecedented development in the number of EIA regulations and guidelines in Africa and South America. As a result, more than a hundred countries adopted the EIA system in 1996 [17, 23]. A common reason for the EIA to spread in many countries is that donors such as the World Bank, the United States Agency for International Development (USAID) and others were asking EIA as part of funding approval process. To date, the EIA is an important tool in environmental management in many developed and developing countries. However, the functioning of the EIA is very different in developing countries. Some countries have clear regulations, others have guidelines and others have unplanned procedures. Glasson and Salvador [18] have also shown that those with well-established procedures cannot guarantee stable practice. Normally, there is no one complete, valid definition of EIA [2]. Often defined as a tool, a methodology and a regulatory requirement but it is primarily a process. According to Aucamp [30], the EIA is defined as a process to assess the potential impacts on the environment of a planned development. Explanations or definitions can be plentiful even if they all involve assessing the significant impacts before making a decision in a timely manner [7, 19]. In a similar perspective, the Rwanda Environmental Management Authority (REMA) [34] also defines the EIA as a systematic, reproducible and multilevel process of identification, prediction and analysis of significant environmental impacts (positive or negative) of a proposed project or activity and its practical alternatives on the physical, biological, cultural and socio-economic characteristics of a particular geographic area in order to provide information necessary for enhancing decision-making. Following this REMA's definition, the EIA is mainly used to prevent or mitigate the adverse effects of major development projects in Rwanda. 
Ministerial Order $\mathrm{N}^{\circ} 004 / 2008$ of $15 / 08 / 2008$ outline the works, activities and projects that have to undertake an environmental impact assessment [12]. Among the projects include: construction and repair of international and national roads, large bridges, industries, factories, hydro-dams and electrical lines, public dams for water conservation, rain water harvesting for agricultural activities and artificial lakes, large hotels public building which accommodate more than one hundred per day, extraction of mines and public landfills. This shows that the level of development and industrialization is also linked to the application of EIA in any country. In the present case, Rwanda is currently characterized by rapid economic development as well as infrastructure development. When this development is not monitored well, it can lead to environmental deterioration. Therefore, it is of importance to analyze the EIA system at national level. The Constitution of the Republic of Rwanda (2003) as amended in 2015, Article 29 states that every citizen is entitled to a healthy and satisfying environment [29]. Environmental challenges today are on the rise due to a lower level of environmental awareness, insufficient technical staff and coordination among sectors across environmental issues. Various solutions to these problems have been introduced since the colonial period. During the colonial times, conservation and establishment of protected areas and reserves was began.

As a tool for sustainable development and poverty reduction in Rwanda, EIA addresses responsible and equitable use of the environment resources and fostering the commitment for environmental protection. As other developing countries, the EIA processes in Rwanda are hindered in many ways. For instance, many developers have a wrong view on EIA as costly and time-consuming constraint on development. On the other hand, EIA benefit the developers because it creates a parallel framework for considering location and design issues and environmental issues $[8,20,32]$.Various authors believe the EIA to be the single and decisive document that promotes sustainable healthy environmental conditions through the "anticipateand-prevent" strategy $[1,9,28,31,38]$. Despite all challenges, sustainable use of the environment must still be the principal goal of the EIA process.

\section{Evaluation Criteria}

To assess the effectiveness of Rwanda's environmental impact assessment system, a set of analytical criteria was used. The criteria applied in this study were based on the evaluation criteria proposed by Wood $[4,6]$ and the quality control criteria used by Ortolano et al [24] and Leu et al [39, 40]. These criteria are divided into two categories used by Fuller [22], namely systemic measures and foundation measures. Systemic measures are designed to provide quality assurance in the practice and administration of EIA, including legislative and administrative frameworks and various aspects of EIA processes, such as screening, scoping, alternatives, public participation, EIA reports review, mitigation and monitoring. Foundation measures are designed to improve the effectiveness of the environmental impact assessment system, including the existence of environmental impact assessment guidelines, training, capacity building, and professional recognition (Table 1). The EIA system in Rwanda was evaluated using several sources of data and information. A review of published and grey literature related to environmental systems in Rwanda was carried out. The relevant documents and guidelines of the EIA were investigated. However, some documents are not typically in the public domain. We analyzed the legislative framework of Rwanda's environmental impact assessment. To ascertain the range of views held on the effectiveness of EIA in Rwanda, we pleaded the opinions of professionals and practitioners involved in the environmental impact assessment process. 
Table 1. Summary of the evaluation criteria for EIA system in Rwanda [4]

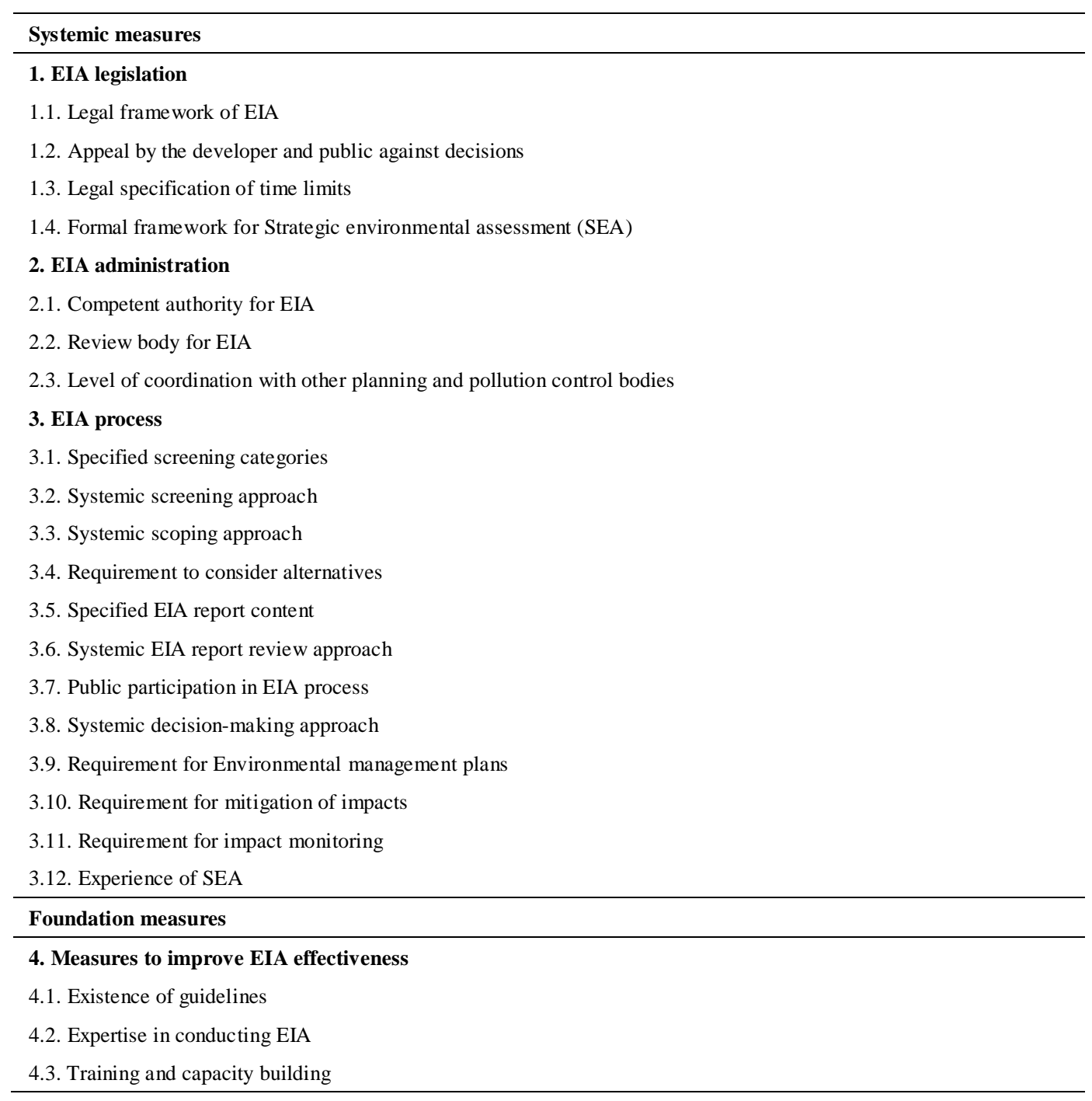

\section{EIA Systemic Measures}

\subsection{Legislative Framework of EIA in Rwanda}

The Constitution of the Republic of Rwanda (2003) amended in 2015 and associate organic law ensure the protection and management of the environment and encourage the rational use of natural resources [10, 11, 29]. Therefore, the legislative basis for Rwanda's environmental impact assessment is the Environmental Organic Law No. 04/2005 of 2005, which determines the modalities of protection, conservation and promotion of environment in Rwanda; Ministerial order No 003/2008 of 2008 relating to the requirements and procedure for environmental impact assessment; and Ministerial order No 004/2008 of 2008 establishing the list of works, activities and projects that have to undertake environment impact assessment. Various socio-economic development policies and strategies, such as "2005-2007 Rwanda Investment and Export Strategic Action Plan" and "Vision
2020", all require the establishment of a standardized environmental management system that should take into account the principles of sustainable development. The organic law (Article 67) requires that projects, plans and policies that may have an impact on the environment must undergo an environmental impact assessment before being authorized to implement them. Article 69 gives REMA legal power to supervise EIA's actions. If REMA rejects the proposed project after reviewing the environmental impact report, the developer can abandon the project, improve and resubmit the revised EIA report, or complaint to the Minister of Environment (MoE). If the developer successfully appeals the decision of the Authority (REMA), the Authority is obliged to release the revised record of the decision to the developer.

Generally, the screening and preparation terms of reference (ToR) takes 40 days, and the time frame for EIA reporting will vary depending on the nature of the project (Figure 1). The duration of the entire review process is 95 days. Similar to the environmental impact assessment 
legislations of the Middle East and North Africa countries [21] and most transition countries and developing countries $[5,18]$, this environmental impact assessment system of Rwanda has some shortcomings that can limit the effectiveness of the environmental impact assessment process. The system failed to promote capacity building and public awareness, and lacked the provisions of the Strategic Environmental Assessment (SEA) [8]. Normally, comprehensive EIA legislation is the foundation of effective EIA process in any country.
Globally, most countries observe some multilateral environmental agreements to protect the planet. Similar in other countries, Environmental Impact Assessment is a great approach that helps Rwanda to achieve its commitments to international environmental agreements. The Government of Rwanda has ratified several international treaties and agreements on environmental protection and sustainable development (Table 2) [33, 35]. In addition, Rwanda has developed some environmental standards (Table 3) [27].

Table 2. Some ratified conventions

\begin{tabular}{|c|c|}
\hline Presidential order, policy or law & Convention description \\
\hline $\mathrm{n}^{\circ} 017 / 01$ of 18 March 1995 & The United Nations Convention on Biological Diversity \\
\hline $\mathrm{n}^{\circ} 78 / 01$ of 8 July 2002 & The United Nations Framework Convention on Climate Change \\
\hline$n^{\circ} 78 / 01$ of 8 July 2002 & The Stockholm Convention on persistent organic pollutants \\
\hline$n^{\circ} 28 / 01$ of 24 August 2003 & $\begin{array}{l}\text { The Rotterdam Convention on the Prior Informed Consent Procedure for Certain } \\
\text { Hazardous Chemicals and Pesticides in International Trade }\end{array}$ \\
\hline$n^{\circ} 36 / 2003$ of 29 December 2003 & The Kyoto Protocol to the Framework Convention on Climate Change \\
\hline$n^{\circ} 35 / 2003$ of 29 December 2003 & The Bonn Convention on conservation of migratory species of wild animals \\
\hline$n^{\circ} 211$ of 25 June 1980 & $\begin{array}{l}\text { The Washington Convention on International Trade in Endangered Species of } \\
\text { Wild Flora and Fauna (CITES) }\end{array}$ \\
\hline n $38 / 2003$ of 29 December 2003 & $\begin{array}{l}\text { The CARTAGENA protocol on biosafety to the Convention on Biological } \\
\text { biodiversity }\end{array}$ \\
\hline n $37 / 2003$ of 29 December 2003 & $\begin{array}{l}\text { The RAMSAR International Convention on Wetlands of International } \\
\text { importance, especially as waterfowl habitat }\end{array}$ \\
\hline$n^{\circ} 29 / 01$ of 24 August 2003 & $\begin{array}{l}\text { The BASEL Convention on the Control of Transboundary Movements of } \\
\text { Hazardous wastes and their disposal }\end{array}$ \\
\hline$n^{\circ} 30 / 01$ of 24 August 2003 & The MONTREAL Protocol on Substances that deplete the Ozone layer \\
\hline Standards & Descrintion \\
\hline ISO 14001: 2004 & EMS (Specification guidance for use) \\
\hline RS ISO 14004: 2004 & EMS (General guidelines on principles, systems and supporting techniques). \\
\hline RS ISO 14015: 2004 & EMS: Environmental Assessment of Sites and Organizations (EASO). \\
\hline RSISO 1450: 2004 & EMS (Vocabularies) \\
\hline RS 555:2011: ISO 19011:2004 & Guidelines for quality and or EMS auditing \\
\hline RS 205-1: 2007 (ISO $14064-1: 2006)$ & $\begin{array}{l}\text { Greenhouse gases-Part 1: Specification with guidance at the organization level for } \\
\text { quantification and reporting of greenhouse gas emissions \& removal }\end{array}$ \\
\hline RS 205-2:2007 (ISO 14064-2:2006) & $\begin{array}{l}\text { Greenhouse gases- Part 2: Specification with guidance at the project level for } \\
\text { quantification, monitoring and reporting of greenhouse gas emissions reductions or } \\
\text { removal enhancements }\end{array}$ \\
\hline RS 205-3:2007 (ISO 14064-3:2006) & $\begin{array}{l}\text { Greenhouse gases- Part 3: Specification with guidance for the validation and } \\
\text { verification on greenhouse gas assertions }\end{array}$ \\
\hline RS 543:2011 (EAS 751:2010) & Air quality - Specification \\
\hline RS 461:2009 & Water quality - Tolerance limits of discharged industrial wastewater \\
\hline RS 462:2009 & Water quality - Tolerance limits of discharged domestic wastewater \\
\hline RS 544:2011: (EAS 752:2010) & Air quality- Tolerance limits of emission discharged to the air by factories \\
\hline RS 565:2011 & Mining and quarrying- Code of practice \\
\hline RS 542:2011 (EAS 750:2010) & Air quality- Emissions to the air by cement factories Guidelines \\
\hline RS 278:2009 (EAS 537-1:2008) & $\begin{array}{l}\text { Measurement of noise emitted by accelerating road vehicles Engineering method } \\
\text { Part 1: } \mathrm{M} \text { and } \mathrm{N} \text { category }\end{array}$ \\
\hline
\end{tabular}




\subsection{Administrative Procedure of EIA in Rwanda}

In order to better address environmental challenges such as soil erosion, deforestation, wetland drainage, water degradation, climate change and the loss of biodiversity, the Government of Rwanda has set up Rwanda Environmental Management Authority (REMA) under Organic Law No.04/2005 of 08/04/2005 [25, 34]. This Law No. 04/2005 of 08/04/2005 determines the modalities of protection, conservation and promotion of environment in Rwanda. REMA is responsible for coordinating and monitoring all aspects of environmental management for sustainable development. To be specific, one of REMA's principle functions is to ensure that EIA is conducted for proposed development projects in both public and private sectors. Since May 2005, Environmental Impacts Assessments are mandatory undertaken for developmental projects in Rwanda.

Established by Organic Law No.53/2008, the Rwanda Development Board (RDB) is now a specialized organ in charge of fast tracking development activities and to facilitate government and private sector in delivering services on development, promoting local and foreign direct investments in Rwanda, and facilitating and helping investors meet environmental standards in the execution of their projects. In this regard, REMA's Department of Environment Impact Assessment, Compliance and Enforcement (DEIACE) was detached and unified with all government agencies responsible for the entire investor experience under one roof into the RDB. Normally, RDB is responsible for business registration, investment promotion, environmental clearances, privatization and specialist agencies which support the priority sectors of ICT and tourism as well as human capacity development in the private sector. Under an agreement of working arrangement, REMA and RDB aimed to facilitate collaboration between the parties with regard to the efficient and effective implementation of transferred responsibilities. Since February 2009, RDB became the EIA administrative body through its unit of Environmental Compliance, Awareness and Cleaner Production. Before the merger, REMA claimed to have a shortage of staff in DEIACE that leads to poor performance considering the large number of EIA applications in the country. Presently, RDB is issuing EIA certificates through the online system on its website (https://rdb.rw/). In developing countries, EIA effectiveness is restricted due to the overlapping roles of several concerned governmental bodies [21]. With regard to the cost of the EIA, Article 69 of the Organic Law (No. 04/2005 of 08/04/2005) stipulates that an environmental impact assessment will be carried out at the expense of the developer. Once approved, the project developer is required to pay an administrative fee to the Environment Fund (FONERWA) to be determined as a percentage of the project estimated cost. Apart from the aforementioned institutions (REMA \& RDB), many relevant stakeholders take part in EIA process in Rwanda [34]. Among those parties include developers, EIA experts (professionals registered with REMA to undertake impact studies), Lead agencies (government ministries or departments), the public, International funding organizations and Academic institutions.

\subsection{EIA Process in Rwanda}

The four stages consist EIA process in Rwanda (Figure 1) [34]. The first stage (Environmental Impact Initiation) involves screening and scoping. The following is an impact study phase, which includes identifying and analyzing the impacts, formulating mitigation and preparing the report. Review of EIA reports and project approval process are entailed through the decision making and authorization stage. Finally, environmental management and follow up phase comes to deal with monitoring aspects of the project during its implementation. By law, the EIA must be carried out before the project is implemented. In case the projects are already implemented (prior to the enactment of the Organic Law of May 1, 2005) or are currently in operation, such projects must carry out environmental audits. EIA report and Project Brief are two types of formal submissions, which represent sequential stages in the EIA process. The latter is an information document that focuses on critical issues and is used by REMA for project screening. The timeframe for the whole EIA procedure in Rwanda can be viewed in Figure 1. The following details refer to the steps in the EIA process. 


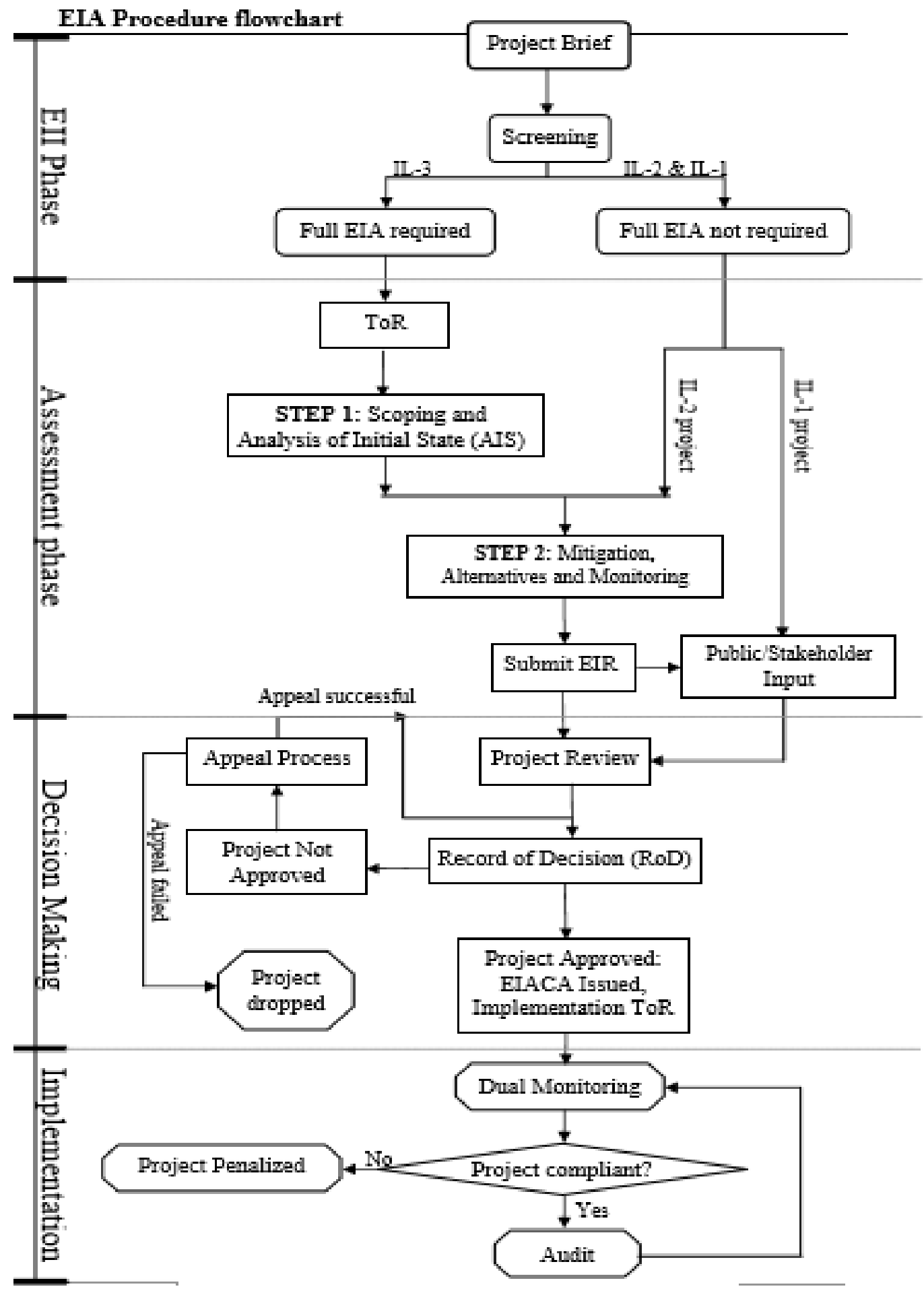

Figure 1. EIA procedure in Rwanda [34].

\subsubsection{Project Brief Submission and Registration}

The project brief serves to provide information on the proposed activity for REMA and lead agencies to determine whether the activity can have significant impacts on the environment, and thus determine the level of EIA needed. The developer of the project has to inform REMA in writing by submission of a Project Brief. A Project Brief submitted to the Authority must at least include: a) Name, title and address of developer; b) Name, purpose, objectives and nature of project, including attributes such as size of project, design, activities that shall be undertaken during and after the establishment of the project, products and inputs, sources of inputs, etc.; c) Description of the proposed project site and its surroundings and alternative sites, if any, where 
the project is to be located; d) Description of how the proposed project and its location conform to existing laws, regulations and policies governing such project and the use of the site/area proposed for its location; e) Any likely environmental impacts that may arise due to implementing various phases/stages of the project and proposed mitigation measures thereto; f) Description of any other alternatives, which are being considered (e.g. siting, technology, construction and operation procedures, sources of raw materials, handling of wastes etc., decommissioning/closure and site restoration); and g) Any other information that may be useful in determining the level of EIA required.

\subsubsection{Screening}

Screening process narrows the application of EIA to projects with potentially significant impacts. Screening carried out by the Authority is a process of determining impact level of a proposed project and then determines the extent of the EIA study. The proposed developmental projects can be categorized as either of impact level (IL) 1, 2 or 3. In this step process, REMA decide whether an EIA is necessary or not, based on the project brief and project screening criteria (Appendix 1). IL 1 refers to the Projects not requiring further environmental analysis. IL 2 refers to the Projects not requiring a full EIA but necessitate further level of assessment. IL 3 consist the Projects requiring a full EIA. Screening enables early identification of environmental issues of major concern and incorporation of appropriate mitigation measures. Screening also enables identification of potential impacts on natural resources, excessive resource consumption and waste generation.

\subsubsection{Scoping and consideration of alternatives}

Scoping aims to identify key issues that need to be addressed in environmental impacts and eliminate unnecessary ones. The developers (or their EIA experts) are responsible for this task. They can consult lead agencies and all relevant stakeholders. Following this step, REMA approves the terms of reference (ToR) for conducting an environmental impact assessment. The consideration of alternatives is also an integral part of EIA procedure that allows for a comprehensive approach to investigate the most appropriate design, process and location for a proposed project [3]. For each project, identification of the possible alternatives is key. By alternatives identification, Project location and process technologies must be considered. Mitigation plan along with an Environmental management plan (EMP) is required for guiding the developer in environmental conservation.

\subsubsection{Public Participation}

IAIA [16] defines public participation as the involvement of individuals or groups that are positively or negatively affected by the proposed project, subjected to planning, development, and decision-making process. Public hearings are essential for an effective, balanced and streamlined environmental impact assessment process. Public hearings benefit not only the public but also developers. Public participation is influenced by the social, cultural and political environment in which EIA occurs [13]. The limited public participation in the EIA process is considered to be the main obstacle to achieving effective EIA in developing countries [5]. Public participation is the cornerstone of Rwanda's environmental impact assessment process. The Authority considers public participation to be a valuable source of information on potential impacts, mitigation measures and feasible alternatives. Public participation aims to improve project design, environmental safety and social acceptability. It is opportune to the public for involvement in scoping, environmental impact report (EIR) review and monitoring. Despite the environmental impact assessment guidelines, implementation is still a challenge due to limited personnel and financial means. However, over time, the public's interest in EIA has increased. The EIA guidelines state that public consultation should be conducted before, during, and after completion of the project. REMA must consider public comments when deciding whether to approve the proposed project.

\subsubsection{EIA report}

The environmental impact study ends with the preparation of a report by the EIA expert(s). The EIA report must provide clear information to the decision-maker on a variety of environmental scenarios without the project, as well as with project and other alternatives [34]. An environmental management program (EMP) should be produced by the developer. Any adjustments made by the developer to the EIA report must be presented as an Environmental Impact Report Addendum. The developer must then submit all the three documents to REMA. The EIA report should entail:

(a) Executive summary of the EIA report

(b) Objectives of the project

(c) Description of the proposal and its alternatives

(d) Discussion on the proposal and its relation to relevant policies, laws and programmes (sectoral and regional).

(e) Description of present (baseline) environmental state (analysis of initial state).

(f) Impact assessment

(g) Evaluation and comparison of alternatives

(h) Impact management and environmental monitoring plan (EMP)

(i) Annex

\subsubsection{EIA Review and Decision-making}

The EIA review ensures that information on the environmental impacts about the project is sufficient before it is used as a basis for decision-making [22]. During the decision-making process, the EIA documents submitted to the Authority are reviewed by two 
decision-making committees: the technical committee and the executive committee established by REMA. Depending on the nature, location, and impact level of the project, the technical committee is composed of experts selected from the authority (EIA department), lead agencies, academic institutions, and recognized experts in the project field. The executive committee shall be composed of three members; the Director General of the Authority (REMA), the Director of the Environmental Impact Assessment Department of the Authority and representative of relevant lead agency. The Executive Committee makes a final decision on the acceptability of the proposed project. If the project is approved, the project developer will obtain an EIA authorization certificate.

\subsubsection{Mitigation and Monitoring}

Mitigation measures are intended to prevent, minimize negative impacts, or compensate for significant adverse impacts [25] and enhance the positive ones. EIA Experts have to develop mitigation measures for IL-3 projects, basing on findings of the environmental impact study. Mitigation measures for IL-2 projects will be based on nature of the project, its components and input of the review committees. The EIA experts must prioritize mitigation measures, organizing them into a hierarchy of importance with highest priority given to measures that prevent highly significant adverse environmental or socio-economic impacts. In regard of Environmental monitoring, REMA and the developer are responsible for monitoring and auditing during implementation and operation of a project. Not only is this done to ensure that the approval conditions are complied with but also to see if the predictions in the EIA reports are true or not. When the impacts exceed the predicted level in environmental impact study, corrective action should be taken. Monitoring also enables REMA to review validity of predictions and conditions of implementation of the Environmental Management Plan (EMP).

\subsubsection{SEA practice experience}

Generally, EIA is particularly needed at the project level, although the concept of sustainable development requires EIA to extend beyond the project level. SEA (Strategic Environmental Assessment) means evaluating the impacts of policies, plans, and programmes beyond the scope of the project. This establishes potential cumulative effects on environment over the long-term. SEA and project level EIA have a close tiering relationship, similar to tiering from policy to project. SEA is an important tool when developing masterplans for development of regions, sectors, provinces, cities, and industrial areas. Unfortunately, there is no such experience yet with SEA in Rwanda [8]. Nationally and worldwide, SEA is very crucial and important for effective integration of decision making with sustainable development and as well restraining environmental degradation.

\section{EIA Foundation Measures}

\subsection{EIA Guidelines}

The fact that there are guidelines for guiding several environmental practitioners is considered a foundational measure to improve the functioning of the environmental impact assessment system [22]. In addition to the organic law and other legislations related to the Environmental Impact Assessment in Rwanda (EIA), a guidance is needed for a more technical nature to streamline the conduct of EIA and appraisal of EIA reports. Therefore, REMA has established "General Guidelines and procedures for Environmental Impact Assessment", which unifies the legal requirements with the practical conduct of EIA, meets a need in the pursuit for sustainable development in Rwanda. The "General Principles and procedures for Environmental Impact Assessment" were developed to help improve the performance of environmental impact assessment in Rwanda. Their purpose is to help companies and individuals involved in environmental impact assessment. The target groups include developers, EIA experts, REMA staff, local environmental committees (provinces, district, sector and cell), lead agencies, experts from research institutions and universities, non-governmental organizations and the general public. The guidelines aim to ensure that EIA participants understand their roles and interpret laws and regulations clearly and consistently. These general guidelines comply with the legal and institutional frameworks on environmental protection in Rwanda and contribute to improvement of quality and efficiency of EIA process in the country. They gradually comply with general global trends and practice of conducting EIA. Rwanda is a fast-growing country in the last few years. Therefore, the 2006 EIA guidelines need update and development of specific guidelines in the sectors they are lacking.

\subsection{Availability of EIA Experts/Consultants and Capacity Building}

Availability of expertise is important for the effectiveness of the EIA system [5]. EIA qualified experts are available in Rwanda. However, it is known that these experts have a small number. REMA uses to update the list of EIA experts year after year. In 2015, there were 75 EIA authorized experts in Rwanda (including individuals and consulting firms). Training and education in EIA contribute to capacity building [14]. EIA is also included in the curriculum of some academic institutions in Rwanda. For instance, University of Rwanda in its science and technology college is releasing trained graduates from different fields related to EIA. This initiative reflects positively in Environmental awareness as well as capacity building of the EIA system [15, 36]. Any individual or consulting firm wishing to conduct EIA studies in Rwanda 
need to apply formally in REMA.

\subsection{Monitoring EIA System}

In order to improve the effectiveness of the EIA system, the performance of the EIA needs to be monitored [15]. This includes monitoring the compliance of predicted impacts and measures to mitigate the actual impacts of completed projects. Researches and reviews about EIA performance can be used to enhance EIA effectiveness. Munyazikwiye [8] assessed the environmental impact assessment (EIA) procedures and challenges faced by environmental officers in EIA implementation in Rwanda. In addition, Kabera [36] claimed EIA inclusion in curricula of universities and higher learning institutions in Rwanda. The present study might be considered as another contribution in that perspective.

\section{EIA Methodology in Rwanda}

EIA methodology is an approach developed to identify, predict and value changes of an action. Changes are reflected in the sequence of activities, steps, as well on the range of environmental issues considered (physical, chemical, biological, socioeconomic, cultural, landscape values and processes). EIA methods range from simple to complex, requiring different kinds of data, different data formats, and varying levels of expertise and technological sophistication for their interpretation. The analyses they produce have differing levels of precision and certainty. Common methods include Ad Hoc method, checklists, Matrix methods, Network diagrams, Overlays (GIS) methods and Modelling method (mathematical model, socio-economic models, species habitat models and expert systems).

In Rwanda, a combination of methods including detailed document review, observation, and interviews, biological and social surveys help in establishing baseline conditions. Impact significance is determined from an impact significance matrix which compares severity of the impact with probability of its occurrence. The scale of intensity of impact is defined on the basis of ecological-toxicological studies and expert judgment. The sensitivity of the receiving environment was determined by specialists based on the baseline data [26].

\section{EIA Challenges \& Solutions}

In his research, Munyazikwiye [8] mentioned some barriers which are still possibly valid for EIA practice in Rwanda. Among others include insufficient baseline data, limited staff in the EIA department, lack of adequate material in the EIA department, the fact that developers consider EIA as a barrier to the implementation of their project, inability to predict the cumulative impacts, shortage of funds to carry EIA studies, lack of training for environmental professionals and finally, poor environmental awareness in the country hinders EIA officers from doing their job effectively [8]. In regard of possible solutions, there is need to carry strategic environmental assessment (SEA) for Rwanda which considers policies, programs and plans. This can help in covering the gap in baseline data. Capacity building is another alternative to consider by increasing the training for environmental officers. In addition, environmental awareness in terms of environmental compliance is highly needed in Rwanda. Regarding policies, there is also a need to update the environmental policies, guidelines and regulations for ease of EIA. The increase in number of staff for EIA department can help either EIA implementation, monitoring and auditing. Last but not least, having an autonomous body for EIA system can increase the effectiveness of EIA.

\section{Conclusions}

The main goal was to analyze the EIA system in Rwanda. The study reveals that the EIA system has strengths and weaknesses. The strengths of the EIA system in Rwanda can be viewed in terms legal framework (environmental laws, ministerial orders on EIA procedures and a list of projects, which must comply with the EIA) and foundation measures (existence of general EIA guidelines). Moreover, political will among the decision makers contribute in EIA practice in Rwanda. On the other hand, there are also some challenges facing the EIA system in Rwanda. EIA methods and Environmental monitoring and audits need to be improved. So far, the administrative system of EIA is not well defined. More EIA researches conducted by local people can contribute a lot for the EIA effectiveness. EIA practice in Rwanda is gradually improving but still there is a need to reinforce the implementation of the stated guidelines for easing the progress of EIA practice.

\section{APPENDIX 1: Project Screening Criteria}

Once a Project Brief has been received and reviewed by the Authority, a proposed project is exempted from further compliance with EIA requirements if all of the following conditions are satisfied:

1) The project will not substantially use natural resources in a way that pre-empts use, or potential use of that resource for any other purpose.

2) Potential residual impacts on the environment are likely to be minor, of little significance and easily mitigated.

3) The type of project, its environmental impacts and mitigation measures are evident and well understood. 
4) Reliable means exist for ensuring that impact management measures can and will be adequately planned and implemented.

5) The project will not displace significant number of people, families or communities.

6) The project is not located in, and will not affect, environmentally-sensitive areas such as:
(a) National parks
(b) Wetlands
(c) Productive agricultural land

(d) Important archaeological, historical and cultural sites

(e) Areas protected under legislation

(f) Areas containing rare or endangered flora or fauna

(g) Areas containing unique or outstanding scenery

(h) Mountains or developments on or near steep hillslopes

(i) Forests

(j) Lakes or their shores

(k) Areas important for vulnerable groups such as fishing communities

(1) Areas near high population concentrations or industrial activities where further development could create significant cumulative environmental problems

(m) Groundwater recharge areas or drainage basins

7) The project will not result in and/or:
(a) Policy initiatives which may affect the environment
(b) Major changes in land tenure
(c) Changes in water use through irrigation, drainage promotion or dams, changes in fishing practices.

8) The project will not cause:
(a) Adverse socioeconomic impact
(b) Land degradation
(c) Water pollution
(d) Air pollution
(e) Damage to wildlife and habitats
(f) Adverse impact on climate and hydrological cycle
(g) Creation of by-products, residual or waste materials which require handling and disposal in a manner that is not regulated by existing authorities.

9) The project will not cause significant public concern because of potential environmental changes. The following are guiding principles:
(a) Is the impact positive, or harmful?
(b) What is the scale of the impact in terms of area, numbers of people or wildlife affected?
(c) What is the intensity of the impact?
(d) What will be the duration of the impact?

(e) Will there be cumulative effects from the impact?

(f) Are the effects politically controversial?

(g) Have the main economic, ecological and social costs been quantified?

(h) Will the impact vary by social group or gender?

(i) Is there any international impact due to the proposed projects?

10) The project will not necessitate further development activity, which is likely to have a significant impact on the environment.

\section{REFERENCES}

[1] A.A. Coşkun \& O. Turker. Analysis of environmental impact assessment (EIA) system in Turkey. Environmental Monitoring and Assessment, 2011. https://doi.org/10.1007/s 10661-010-1507-3

[2] B. Noble. Introduction to Environmental Impact Assessment, Oxford university Press, Canada, 2006.

[3] B. Noble. Introduction to Environmental Impact Assessment: A Guide to Principles and Practice, Oxford University Press, Oxford, 2010.

[4] C. Wood. Comparative evaluation of environmental impact assessment systems. In: Petts J, editor. Handbook of environmental impact assessment, vol. 2. Oxford: Blackwell, 1999. pp. 10-34.

[5] C. Wood. Environmental impact assessment in developing countries. In International Development Planning Review, 2003. https://doi.org/10.3828/idpr.25.3.5

[6] C. Wood. Environmental impact assessment: a comparative review. Harlow: Longman, 1995.

[7] Economic Commission for Africa (ECA). Review of Application of Environmental Impact Assessment in Selected African Countries, Addis Ababa, 2005.

[8] F. Munyazikwiye. An assessment of environmental impact assessment (EIA) procedures and challenges faced by environmental officers in EIA implementation in Rwanda Master's thesis, University of KwaZulu-Natal, Westville Campus, 2011.

[9] G. Hilson. Defining "cleaner production" and "pollution prevention" in the mining context. Miner. Eng. 16 (4), 305$321,2003$.

[10] Government of Rwanda (GoR). Organic Law Determining the Modalities of Protection, Conservation and Promotion of Environment in Rwanda, Kigali, 2005.

[11] Government of Rwanda (GoR). Organic Law Determining the Organization, Functioning and Responsibilities of Rwanda Environment Management Authority, Kigali, 2006.

[12] Government of Rwanda(GoR). Ministerial Order Establishing the List of Works, Activities and Projects that 
Have to Undertake an Environment Impact Assessment, Government printer, Kigali, 2008.

[13] H. Abaza. Strengthening Future Environmental Assessment Practice and International Perspective," In: N. Lee and C. George, Eds., Environmental Assessment in Developing Countries: Principles, Methods and Practice, Wiley, Hoboken, 2000, pp.271-282.

[14] H. Naser. Using Macrobenthos as a Tool in Ecological Assessment: Application in Environmental Impact Assessment (EIA)," Lambert Academic Publishing, Saarbrucken, 2010.

[15] H.A. Naser. Evaluation of the Environmental Impact Assessment System in Bahrain. Journal of Environmental Protection, 2012. https://doi.org/10.4236/jep.2012.32029

[16] International Association of Impact Assessment (IAIA), "Public Participation Best Practice Principles," IAIA, Midlothian, 2006

[17] J. Benson. What is the alternative? Impact assessment tools and sustainable planning, Impact Assessment and Project Appraisal, 21 (4), 261-280, 2003.

[18] J. Glasson \& N.N.B. Salvador. EIA in Brazil: A procedures-practice gap. A comparative study with reference to the European Union, and especially the UK. Environmental Impact Assessment Review, 2000. https://doi.org/10.1016/S0195-9255(99)00043-8

[19] J. Glasson, R. Therivel and A. Chadwick. Introduction to Environmental Impact Assessment, Third edition, Routledge, New York, 2005.

[20] J. Glasson, R. Therivel and A. Chadwick. Introduction to Environmental Impact Assessment, Second edition, Spon press, London, 1999.

[21] K. El-Fadl \& M. El-Fadel. Comparative assessment of EIA systems in MENA countries: Challenges and prospects. Environmental Impact Assessment Review, 2004. https://doi.org/10.1016/j.eiar.2004.01.004

[22] K. Fuller. Quality and quality control in environmental impact assessment. In: Petts J, editor. Handbook of environmental impact assessment, vol. 2. Oxford: Blackwell, 1999. pp. 35-70.

[23] L. Mokhehle and R. Diab. Evolution of environmental impact assessment in a small developing country: a review of Lesotho case studies from 1980 to 1999, Impact Assessment and Project Appraisal, 19 (1), 9-18, 2001.

[24] L. Ortolano, B. Jenkins and R. Abracosa. Speculations on when and why EIA is effective. Environ Impact Assess Rev, 1987;7:285- 92 .

[25] M. Marara, N. Okello, Z. Kuhanwa, W. Douven, L. Beevers \& J. Leentvaar. The importance of context in delivering effective EIA: Case studies from East Africa. Environmental Impact Assessment Review, 31(3), 286-296, 2011. https://doi.org/10.1016/j.eiar.2010.10.002
[26] Ministry of Infrastructure (MININFRA). Environmental and Social Impact Assessment of the Six Secondary Cities and Agatare of CoK, MININFRA, Kigali, Rwanda, 2016.

[27] Netherlands Commission for Environmental Assessment (NCEA) in Rwanda, 16 February 2015.

[28] O.D. Elvan. Analysis of environmental impact assessment practices and legislation in turkey. Environmental Science and Policy, 2018. https://doi.org/10.1016/j.envsci.2018.02.0 08

[29] Official Gazette of the Republic of Rwanda, Year $44 n^{\circ} 9$, 1st May 2005. Organic Law $n^{\circ} 04 / 2005$ of 08/04/2005, determining the modalities of protection, conservation and promotion of environment in Rwanda.

[30] P. Aucamp. Environmental Impact Assessment: A Practical Guide for the Discerning Practitioners, Van Schaik Publishers, Pretoria, 2009.

[31] P.J. LeBlanc and R. Manitowabi. Introducing the concept of follow-up in the Canadian environmental assessment act. Environments 23 (1), 101, 1995.

[32] R. Morgan. Methodological Perspective of Environmental Impact Assessment, Kluwer Academic Publisher, London, 2002.

[33] Rwanda Environment Management Authority (REMA). Final Report, Guidelines for Environmental Impact Assessment for Wetland management In Rwanda,Kigali, 2009.

[34] Rwanda environmental management authority (REMA). General guidelines and procedure for environmental impact assessment (EIA) in Rwanda, Kigali, 2006.

[35] Rwanda stones \& construction Ltd Co (RSC). Environmental Impact assessment (EIA) report for a stone crushing factory, Rwanda, 2011.

[36] T. Kabera. Environmental impact assessment in higher education institutions in East Africa: the case of Rwanda Environmental Science and Pollution Research, 2017. https://doi.org/10.1007/s11356-017-8525-4

[37] United Nations Environment Programme (UNEP). Environmental Impact Assessment and Strategic Environmental Assessment: Towards an Integrated Approach, UNEP, Geneva, 2004

[38] W.A. Ross. Environmental impact assessment in the Philippines: progress, problems, and directions for the future. Environ. Impact Asses. Rev. 14 (4), 217-232, 1994.

[39] W.S Leu, W.P Williams and AA.W. Bark. Quality control mechanisms and environmental impact assessment effectiveness with special reference to the UK. Proj Appraisal, 1996;11:2-12.

[40] W.S. Leu, W.P Williams and A.W. Evaluation of environmental impact assessment in three Southeast Asian nations. Proj Appraisal, 1997;12:89 - 100. 